\title{
The Relation between Insight and Quality Of Life among Schizophrenic Patients.
}

\author{
Nahed Ahmed Morsy \\ Assistant Professor of Psychiatric and Mental Health Nursing, \\ Faculty of Nursing, Tanta University \\ Mervat Hosny Shalaby \\ Lecturer of Psychiatric and Mental Health Nursing, \\ Faculty of Nursing, Tanta University \\ Ayat Saif-elyazal \\ Clinical demonstrator, Psychiatric and Mental Health Nursing, \\ Faculty of Nursing,Tanta University
}

\section{$\underline{\text { Abstract }}$}

Background: There has been considerable growth in literature on insight in schizophrenia and its impact on adherence, symptoms and functioning. Between $50 \%-80 \%$ of patients with schizophrenia are partially or totally lacking insight into the presence of their mental illness. Lack of insight is the most prevalent symptom in schizophrenic disorders, it also occurs more frequently in schizophrenia than in other psychotic disorders. The study of quality of life (QOL) and the focus on patients' subjective sense of well-being is a fairly new phenomenon that has attracted professional attention only within the past two decades. So, issues of life quality became a key when cure is impossible. The present study determines the relation between insight and quality of life among schizophrenic patients. This study followed the descriptive design. It was conducted at the Psychiatric Department of Tanta University Hospital and Tanta Mental Hospital. The subjects of the study consisted of sixty schizophrenic patients. Three tools were used: 1- A structured interview questionnaire was applied for collection of data related to sociodemographic and clinical characteristics of the study subjects, 2- A Scale to assess Unawareness of Mental Disorder (SUMD ) and 3Schizophrenia Quality of Life Scale ( SOLS ).The main results revealed that general insight into mental disorder was negatively related to quality of life as a whole. Insight into mental disorder was negatively related to quality of life in the domains of psycho-social functioning and emotional well-being. But, no relation was found between insight into mental illness and quality of life in the domains of motivation and energy and the domain of medication 
adherence and side effects. This study recommended that the future interventions and research could be directed to help persons with schizophrenia overcome their negative beliefs and find newer and more adaptive ways to think of themselves and their futures, thus allowing for the acceptance of mental illness to have fewer devastating effects.

\section{Introduction}

Schizophrenia is a chronic disorder with a heterogeneous presentation, marked by an array of symptomatology, variations in outcome and responses to treatment. Rates of schizophrenia are very similar from country to country -about $1 \%$ of the population. In the Egyptian population, about $1 \%$ which is almost the same prevalence throughout the world. ${ }^{(1,2)}$ The course of schizophrenia is largely characterized by acute psychotic episodes, which often require hospitalization. Symptomatology is split into two clusters (1) positive symptoms delusions, hallucinations, conceptual disorganization, suspiciousness, agitation, and hostility. ${ }^{(2)}$ Negative symptoms - blunted affect, emotional and social withdrawal, lack of spontaneity and poverty of speech. These disturbances have the propensity to have a pervasive impact on many areas of life functioning and subsequently on quality of life (QOL). ${ }^{(3)}$ The long -term course of schizophrenia is frequently characterized by reducing social and occupational functioning, loss of independent living, impaired quality of life, substance abuse, and increased risk of suicidal and violent behavior. $^{(4)}$

There has been considerable growth in literature on insight in schizophrenia and its impact on adherence, symptoms, and functioning. Between 50\%-80\% of patient with schizophrenia are partially or totally lacking insight into the presence of their mental illness. ${ }^{(4)}$ El-maadawy (1997) found that $97.5 \%$ of the hospitalized psychotic patients were completely unaware of their mental illness. ${ }^{(5,6)}$ Insight of illness is an important aspect in diagnosis and treatment of patients with mental disorders. Focus has primarily been on awareness of illness and treatment needs based on the widely used definition by Anthony David; Aaron T. Beck labeled this clinical insight. In addition to attenuated clinical insight, patients with psychosis often have reduced capacity to reflect rationally on their 
anomalous experiences and to recognize that their conclusions are incorrect. Beck termed such insight cognitive insight. He summarized the relevant components of this concept as "impairment of objectivity about the cognitive distortions, loss ability to put these into perspective, resistance to corrective information from others and over confidence in conclusions." ${ }^{(7,8)}$ Lack of insight has been labeled with different terms (i.e., "unawareness of illness") and has been conceptualized from several theoretical perspectives. The scientific interest in lack of insight has recently increased and different assessment methods have been developed. The etiopathogenic mechanisms of lack of insight are yet unknown, although several hypotheses have been suggested. At first lack of insight was understood as denial of illness. In other words, an abnormal coping mechanism or abnormal psychological defense was held to arise from the failure of adaptive coping mechanism or from a reaction of the split healthy mind against the irruption of illness in the self. Lack of insight is the most prevalent symptom in schizophrenic disorders, it's also occurs more frequently in schizophrenia than in other psychotic disorders. However, lack of insight has been included in only one of the criteria for the diagnosis of schizophrenia. ${ }^{(9)}$

The study of quality of life (QOL) and the focus on patients' subjective sense of wellbeing is a fairly new phenomenon that has attracted professional attention only within the past 2 decades. Between 1850 and 1950, medicine was dominated by the quest for cures; treating chronic illness as well as helping patients manages long-term impairment received less attention. However, this trend has shifted. Issues of life quality become key when cure is impossible. Illness that cannot be eliminated must be managed, and the treatment goal becomes maintaining maximum function and a meaningful existence or QOL. ${ }^{(10)}$ Some researchers have conceptualized QOL largely as a subjective affair that only the patient can report, whereas others have argued for the importance of including more "objective" indicators of QOL, such as housing and health status, or frequency of social interactions. Both sides of this argument are equally compelling ${ }^{(11,12)}$ While interest has grown steadily in understanding how persons with schizophrenia appraise their disorder and subsequent needs, the nature 
of the impact of awareness or admission of disorder on various domains of quality of life has remained a matter of considerable debate. At the level of both theory and empirical study it has been alternately held that acknowledgement of one's mental illness is a detriment and a key to successful adaptation. From one perspective, acceptance of illness has been advanced as a key to making informed decisions about one's future, to free oneself from blame for difficulties linked with illness and to forming bonds with others who are aware of one's difficulties. From another view, however, "awareness of illness" has been suggested to represent the acceptance of a system of social power in which one's individuality and dignity is at risk of being diminished. Indeed empirical studies suggest both awareness and lack of awareness have significant risks associated with them. ${ }^{(13)}$

Controversy exists as to the cognitive, emotional, and behavioral consequences of this lack of insight for the person with schizophrenia. Some care provider and some care consumers strongly insist that insight into a psychiatric disorder is a necessary step toward compliance with treatment, recovery, and rehabilitation for persons with disability .Other providers and care consumers argue that acquiring insight into a disorder and acknowledging that one has schizophrenia can lower self esteem and increase the despair, helplessness, and hopelessness of the person with the psychiatric disorder and decrease wellbeing and quality of life. ${ }^{(14)}$ Furthermore, other studies demonstrate that poor insight has shown a pattern of apparently contradictory association with outcomes. For instance, poor insight has been linked to poorer treatment adherence, poorer clinical outcomes, poorer social functions, vocational dysfunction and difficulties in developing working relationships with health care professionals. ${ }^{(15)}$

Finally, before possibly proposing that insight must be encouraged, researcher should review studies that have investigated potentially negative implications of gain insight, such as depression and suicide which affect negatively on various aspects of patients quality of life. ${ }^{(4)}$

\section{Aim of the study}

The aim of the study was to determine the relation between insight and quality of life among schizophrenic patients. 


\section{Materials and method}

Study design: The design followed in this study is a descriptive design

Setting: The study was conducted at the Psychiatric Department of Tanta University Hospital and Tanta Psychiatric and Mental Health hospital, the later is affiliated to the Ministry of Health . These two hospitals serve three governorates, namely El-Gharbeya, El-Menofeya, and Kafr-El-Sheikh. They have a capacity of 80 beds. They are composed of eight wards (four for males and four for females).

Subjects: The subjects included sixty schizophrenic patients, of both sexes, fulfilling the following criteria:

1-Patients who passed the acute stage and able to communicate.

2. Patients who have been stayed in hospital not less than 2 months.

All patients who were available at the time of data collection and who fulfilled the inclusion criteria were included in the study until the assigned number(60) has been completed.

Tools of the study: The data of the study have been collected using the following tools:

\section{Tool I: Socio-demographic and clinical} data structured interview questionnaire: a-Socio-demographic characteristics namely (age, sex, occupation, level of education, marital status, residence, family size)

b-Clinical characteristics of the study group that included: diagnosis, age of onset of psychotic illness, number of previous psychiatric hospitalization, date of admission,durationofcurrenthospitalization , mode of admission as reported by patients , the family history, medications presently taken and its side effects).

Tool II: A Scale to assess Unawareness of Mental Disorder (SUMD):

This scale has been developed by Amador et al (1993).(18) This scale was applied on Egyptian Psychiatric population by ElMaadawy (1997).(4) It has been evaluated for validity and reliability. The scale was reported to be valid. As for its reliability interclass correlation coefficients (ICC) ranged from 0.69 to $0.99($ median $=0.84)$, 0.52 to $0.99($ median $=0.71)$ and 0.48 to 0.99 (median 0.64 ) respectively.

The scale attempts to measure specific and global aspects of awareness and also 
assesses patient's attributions about the cause of different signs and symptoms. It represents a comprehensive and detailed approach to insight. The scale has 20 items which are:

Three general items namely :( awareness of having mental disorder, awareness of achieved effects of medication and awareness of the social consequences of mental disorder)

Two subscale items (fourth and fifth dimension of insight) consisting of: awareness of specific signs and symptoms (items 4a-20a) and attribution of specific signs and symptoms (items 4b-20b). Awareness relates to the recognition of the signs and symptoms of illness while attribution refers to explanations as to the cause or source of these signs and symptoms. Rating for the general items was as follows: $1=$ complete awareness, $2=$ aware, $3=$ somewhat aware , 4= unaware , and $5=$ completely unaware.

This rating was applied also on assessing awareness of symptoms. For each symptom-item on the scale, it must be first ascertained that the subject has exhibited this particular symptom during the period under the investigation. The severity of symptoms is not relevant, only that it is clearly present. The symptom checklist must be completed prior to filling out the scale in order to determine which symptom items are relevant. The three non-symptom items 1,2 , and 3

( awareness of having mental disorder, awareness of achieved effects of medication and awareness of the social consequences of mental disorder, respectively) are usually relevant and should be completed if this is the case.

Following each symptom item (\# 4-20), subject understandings of the cause of the symptom (i.e., attribution) was rated only if the subject obtained a score between 1 and 3 on awareness item. Rating attribution was as follows: $1=$ correct attribution, $2=$ not fully correct attribution, $3=$ partial attribution , $4=$ distorted attribution , $5=$ incorrect attribution. The score for each of the first three dimensions of SUMD (awareness of having mental disorder, awareness of achieved effects of medication and awareness of the social consequences of mental disorder) ranges from 1 to 5 . subscale total score is obtained by summing up the completed items $4 a-20 a$ divided by the number of items completed for awareness items . Then by summing up the completed items 
$4 b-20 b$ divided by the number of items completed for attribution items . Therefore, the potential ranges are 1 to 5 for the subscale items. The total SUMD score is calculated by summing up the ratings of the five dimensions. This can range from 5 to 25 in which score (5) reflects complete insight, score (15) denotes that the patient has moderate lack of insight. where as score (25) refers to severe lack of insight.

\section{Tool III: "Schizophrenia Quality of Life}

\section{Scale (SQLS)":}

The scale was developed and tested for validity and internal reliability by Wilkinson et al. (2000), and demonstrated good internal consistency. The scale was translated into Arabic language and tested for its validity and reliability. ${ }^{(19)}$ The scale comprises 30 statements to be answered on five points likert scale

1.type ranging from : "Never" (0) to "Always" (4). Some questions in the motivation and energy domain $(12,13,15,20)$ have reversed scores that ranges from "Never" (4) to “Always" (0). Higher scores indicate perceived poor quality of life, while lower scores indicate good quality of life. / The scale was divided into three subscales addressing different dimensions about impact of schizophrenia on quality of life .It includes:

\section{1- Psychosocial functioning :}

Covering various emotional and social problems, for examples feeling of loneliness ,difficulty mixing in social situations ,feeling of people avoidance, feeling angry, feeling of jumpiness and edgy, feeling of hopelessness, feeling of being down and depression, and feeling worried about future....etc. The functioning is measured by 15 questions $(4,7,8,9,11,14,16,18,19,22,24,26,27,28,29)$.

\section{Motivation and energy:}

Addressing various problems of motivation and activity, such as ability to carry out daily activities, lacking the will to do things and preferring to stay at home etc. The motivation and energy is measured by 7 questions $(1,6,12,13,15,17,20)$.

\section{Side effects of the medication:}

Including issues such as sleep disturbance, blurred vision, muscles twitches, muscles stiffness, and dry mouth due to side effects of medications etc. Side effects score is measured by 8 questions $(2,3,5,10,21$, 23,25 , and 30). 


\section{Method}

An official written approval was obtained from the head of Psychiatric department at Tanta University Hospitals and Tanta Psychiatric and Mental Health Hospital.

\section{Pilot study:}

A pilot study was carried out on a sample of six schizophrenic patients who had duration of illness not less than two months; and selected randomly after obtaining their oral consent to participate in the study, those patients were excluded later from the actual study sample. The aim of the pilot study to ascertain the clarity and applicability of the study tools and to identify any obstacles that may be faced during data collection. The pilot study proved the applicability of the study tools

\section{Actual study}

A survey of all hospital wards was done through reviewing all patients' charts in order to identify those who were meeting the inclusion criteria.

An oral consent was obtained from the patients before starting the study. Schizophrenic patients who meet the inclusion criteria were asked to participate in the study after establishing rapport and trusting relationship and explaining the aim of the study.
The form of the study tools was then explained to the patients and the patients were reassured that all information will be confidential and used only for the purpose of the study. patient's attention, concentration, willingness to operate or talk. Patient's clinical data were double checked from their clinical charts .

Each selected patient was interviewed individually by the researcher using the study tools ( tool I,II, III). The symptom checklist.

items was completed prior to filling out the SUMD ( tool II ) in order to determine which symptom items are relevant Each interview lasted from 4560 minutes according to the Data were collected during a period of three hours per day in three days per week for three months starting from March 2010 to May 2010 . Data were then categorized by the researcher, checked and revised by the supervisors of the thesis.

\section{Statistical analysis:}

The collected data was organized, tabulated and statistically analyzed using SPSS soft ware statistical computer package version 13. For quantitative data, mean and standard deviation were calculated. For qualitative data, the number 
and percentage distribution was calculated chi square was used as test significance. Significance was adopted at Value <0.05 for interpretation of results of test of significance.

\section{Result}

Table (1) : Illustrates the distribution of the studied schizophrenic patients according to their socio-demographic characteristics. It was found that $60 \%$ of patients were male, and $40 \%$ were females. The highest percentage of the studied patients had age range between 40 to $<60$ years represent $53.3 \%$, those who had age range between 20 to $<40$ years represent $21.6 \%$ and who had an age $\geq 60$ represent $25.1 \%$. The difference between the three groups, regarding the age, was statistically not significant $\left(\chi^{2}=0.49, \mathrm{P}\right.$ > $0.05)$. The table also presents the residence of the studied patients, denoting that $58.4 \%$ of them living in rural area, while $41.6 \%$ were from urban area. The difference between the two groups, regarding the residence of the studied patients, was statistically not significant $\left(\chi^{2}=0.09, \mathrm{P}>0.05\right)$.

Regarding to their level of education, it appears from this table that $35.0 \%$ of the studied patients were illiterate, $23.3 \%$ of them can only read and write, $18.4 \%$ had basic education, $13.3 \%$ had secondary education, while the lower percentage of the studied patients (10.0\%) had university and higher education. The difference between the five groups, regarding their level of education, was statistically not significant $\left(\chi^{2}\right.$ $=3.52, \mathrm{P}>0.05)$. As regards to occupation, $33.4 \%$ of the studied patients were unemployed, and manual workers represented $26.6 \%$. Employee represented $21.6 \%$ of the studied patients, while the professionals were $18.4 \%$. The difference between the four groups, regarding their occupation, was statistically not significant $\left(\chi^{2}=1.34, \mathrm{P}>\right.$ $0.05)$.It was also found that $41.6 \%$ of the studied patients were married, while $58.4 \%$ were unmarried. The difference between the two groups, regarding their marital status, was statistically not significant $\left(\chi^{2}=0.05, \mathrm{P}\right.$ $>0.05)$. The table also presents the majority of the studied patients (66.6\%) live with their family, and only $33.4 \%$ of the patients live alone. The difference between the two groups, regarding their Co-habitation was statistically not significant $\left(\chi^{2}=0.01, \mathrm{P}\right.$ > 0.05).

Table (2) : Illustrates the distribution of the studied schizophrenic patients according to their clinical data. From this table appears that the duration of illness among $38.4 \%$ of the studied patients was between 5 to 10 
years, while only $30.0 \%$ of them had a duration of illness less than 5 years. The difference between the three groups, regarding the duration of illness, was not statistically significant $\left(\chi^{2}=0.27, \mathrm{P}\right.$ > $0.05)$. Three quarters of the studied patients $(75.0 \%)$ were admitted to the hospital against their will, and the rest of them $(25.0 \%)$ were admitted voluntary in the last hospital admission. The difference between the two groups, regarding Way of last hospitalization, was not statistically significant $\left(\chi^{2}=0.02, \mathrm{P}>0.05\right)$. The table also shows that there is a variation among the studied patients regarding the number of hospitalization. $25.0 \%$ of the studied patients were admitted from 1 to 3 times to the hospital, $35.0 \%$ were admitted from 4 to 6 times, while $40.0 \%$ of the studied patients were admitted more than 7 times. The difference between the three groups, regarding frequency of hospitalization(s) was not statistically significant $\left(\chi^{2}=1.15\right.$, $\mathrm{P}>0.05$ ).

Table (3) : It was found that nearly half of the studied patients $(46.6 \%)$ had poor insight, 35\% had fair insight while only
$18.4 \%$ of them had good insight. The difference, regarding insight, was not statistically significant $\left(\chi^{2}=0.93, \mathrm{P}>\right.$ 0.05).

Table (4): It was found that more over half of studied patients $(51.6 \%)$ had poor quality of life, $35.0 \%$ of them reported moderate quality of life, while only $13.4 \%$ had good quality of life. The difference, regarding quality of life was not statistically significant $\left(\chi^{2}=0.07, \mathrm{P}>\right.$ 0.05).Table (5) shows the Insight into mental illness distribution by quality of life of the studied schizophrenic patients. The highest frequency of patients with good insight (54.5\%) was observed among the group with poor quality of life, while the highest frequency of patients with poor insight (50.0\%) was noticed among the group with fair quality of life. Also, the highest frequency of patients with fair insight (76.2\%) was observed among the group with poor quality of life. The difference between the three groups, regarding the Insight into mental illness, was statistically significant $\left(\chi^{2}=9.823, \mathrm{P}<\right.$ $0.05)$. 
Table (6) shows the Insight into mental illness distribution by psychosocial functioning of the studied schizophrenic patients. The highest frequency of patients with good insight (54.5\%) was observed among the group with poor psychosocial functioning, while the highest frequency of patients with poor insight (50.1\%) was noticed among the group with good psychosocial functioning. Also, the highest frequency of patients with fair insight (33.3\%) was observed among the group with good motivation and energy. Also, the highest frequency of patients with fair insight (61.9\%) was observed among the group with poor motivation and energy with fair psychosocial functioning. The difference between the three groups, regarding the Insight into mental illness, was statistically significant $\left(\chi^{2}=9.654, \mathrm{P}<0.05\right)$.

Table (7) shows the Insight into mental illness distribution by motivation and energy of the studied schizophrenic patients. The highest frequency of patients with good insight $(45.5 \%)$ was observed among the group with poor motivation and energy, while the highest frequency of patients with poor insight $(46.4 \%)$ was noticed among the group. The difference between the three groups, regarding the Insight into mental illness, was not statistically significant $\left(\chi^{2}=6.758, \mathrm{P}>0.05\right)$. 
Tanta Scientific Nursing Journal

Table(1): Socio-demographic data of the studied schizophrenic patients $(n=60)$ :

\begin{tabular}{|c|c|c|c|c|c|c|c|}
\hline \multirow{2}{*}{$\begin{array}{c}\text { Personal } \\
\text { Characteristics }\end{array}$} & \multicolumn{2}{|c|}{$\begin{array}{l}\text { Males } \\
(\mathbf{n}=35)\end{array}$} & \multicolumn{2}{|c|}{$\begin{array}{l}\text { Female } \\
(n=25)\end{array}$} & \multicolumn{2}{|c|}{$\begin{array}{c}\text { Total }(\mathbf{n}= \\
60)\end{array}$} & \multirow[t]{2}{*}{$\begin{array}{c}\text { Test of } \\
\text { significance }\end{array}$} \\
\hline & No. & $\%$ & No. & $\%$ & No. & $\%$ & \\
\hline Age & & & & & & & \multirow{4}{*}{$\chi^{2}=0.49$} \\
\hline $20-$ & 7 & 20.0 & 6 & 24.0 & 13 & 21.6 & \\
\hline $40-$ & 20 & 57.2 & 12 & 48.0 & 32 & 53.3 & \\
\hline$\geq 60$ & 8 & 22.8 & 7 & 28.0 & 15 & 25.1 & \\
\hline \multicolumn{7}{|l|}{ Residence } & \multirow{3}{*}{$\begin{array}{l}\chi^{2}=0.09 \\
P=0.965\end{array}$} \\
\hline Rural & 21 & 60.0 & 14 & 56.0 & 35 & 58.4 & \\
\hline Urban & 14 & 40.0 & 11 & 44.0 & 25 & 41.6 & \\
\hline \multicolumn{7}{|l|}{ Education } & \multirow{7}{*}{$\begin{array}{l}\chi^{2}=3.52 \\
P=0.474\end{array}$} \\
\hline Illiterate & 10 & 28.5 & 11 & 44.0 & 21 & 35.0 & \\
\hline Read and write & 8 & 22.8 & 6 & 24.0 & 14 & 23.3 & \\
\hline Basic education & 6 & 17.2 & 5 & 20.0 & 11 & 18.4 & \\
\hline Secondary & 6 & 17.2 & 2 & 80 & 8 & 13.3 & \\
\hline education & & & & & & & \\
\hline $\begin{array}{c}\text { University and } \\
\text { higher }\end{array}$ & 5 & 14.3 & 1 & 4.0 & 6 & 10.0 & \\
\hline Marital status & & & & & & & $\chi^{2}=0.05$ \\
\hline
\end{tabular}


Tanta Scientific Nursing Journal

\begin{tabular}{|c|c|c|c|c|c|c|c|}
\hline Married & 15 & 42.8 & 10 & 40.0 & 25 & 41.6 & \multirow[t]{2}{*}{$P=0.826$} \\
\hline Unmarried & 20 & 57.2 & 15 & 60.0 & 35 & 58.4 & \\
\hline \multicolumn{7}{|l|}{ Occupation } & \multirow{5}{*}{$\begin{array}{l}\chi^{2}=1.34 \\
P=0.720\end{array}$} \\
\hline Unemployed & 13 & 37.1 & 7 & 28.0 & 20 & 33.4 & \\
\hline Manual work & 10 & 28.5 & 6 & 24.0 & 16 & 26.6 & \\
\hline Employee & 6 & 17.2 & 7 & 28.0 & 13 & 21.6 & \\
\hline Professional & 6 & 17.2 & 5 & 20.0 & 11 & 18.4 & \\
\hline \multicolumn{7}{|l|}{ Co-habitation } & \multirow{3}{*}{$\begin{array}{l}\chi^{2}=0.01 \\
P=0.926\end{array}$} \\
\hline Alone & 12 & 34.3 & 8 & 32.0 & 20 & 33.4 & \\
\hline $\begin{array}{l}\text { With his or/ her } \\
\text { family }\end{array}$ & 23 & 65.7 & 17 & 68.0 & 40 & 66.6 & \\
\hline
\end{tabular}


Table(2): Clinical characteristics of the studied schizophrenic patients $(n=60)$ :

\begin{tabular}{|c|c|c|c|c|c|c|c|c|}
\hline \multirow{2}{*}{ Clinical data } & \multicolumn{2}{|c|}{ Males } & \multicolumn{2}{|c|}{$\begin{array}{c}\text { Female } \\
\text { (n=3 5) }\end{array}$} & \multicolumn{2}{|c|}{$\begin{array}{c}\text { Total (n= 25) } \\
\text { (n) }\end{array}$} & $\begin{array}{c}\text { Test of } \\
\text { significance }\end{array}$ \\
\cline { 2 - 7 } & No. & \% & No. & \% & No. & \% & \\
\hline Duration of \\
illness
\end{tabular}


Table (3) : The score of insight into mental illness among studied schizophrenic patients $(\mathrm{n}=$ 60):

\begin{tabular}{|c|c|c|c|c|c|c|c|}
\hline \multirow[t]{2}{*}{ Score } & \multicolumn{2}{|c|}{$\begin{array}{c}\text { Male } \\
(n=35)\end{array}$} & \multicolumn{2}{|c|}{$\begin{array}{l}\text { Female } \\
(n=25)\end{array}$} & \multicolumn{2}{|c|}{$\begin{array}{c}\text { Total } \\
(n=60)\end{array}$} & \multirow[t]{2}{*}{$\begin{array}{c}\text { Test of } \\
\text { significanc } \\
\text { e }\end{array}$} \\
\hline & No. & $\%$ & No. & $\%$ & No. & $\%$ & \\
\hline $\begin{array}{c}\text { Good } \\
5-\end{array}$ & 5 & 14.3 & 6 & 24.0 & 11 & 18.4 & \multirow{4}{*}{$\begin{array}{l}\chi^{2}=0.93 \\
P=0.629\end{array}$} \\
\hline $\begin{array}{c}\text { Fair } \\
10-\end{array}$ & 13 & 37.2 & 8 & 32.0 & 21 & 35.0 & \\
\hline $\begin{array}{l}\text { Poor } \\
20-25\end{array}$ & 17 & 48.5 & 11 & 44.0 & 28 & 46.6 & \\
\hline Total & 35 & $\overline{58.4}$ & 25 & 41.6 & 60 & $\begin{array}{c}100 . \\
0\end{array}$ & \\
\hline
\end{tabular}


Table(4): The score of quality of life among studied schizophrenic patients $(n=60)$ :

\begin{tabular}{|c|c|c|c|c|c|c|c|}
\hline \multirow[t]{2}{*}{ Score } & \multicolumn{2}{|c|}{$\begin{array}{c}\text { Male } \\
(n=35)\end{array}$} & \multicolumn{2}{|c|}{$\begin{array}{l}\text { Female } \\
(\mathrm{n}=25)\end{array}$} & \multicolumn{2}{|c|}{$\begin{array}{c}\text { Total } \\
(n=60)\end{array}$} & \multirow[t]{2}{*}{$\begin{array}{c}\text { Test of } \\
\text { significanc } \\
\mathrm{e}\end{array}$} \\
\hline & No. & $\%$ & No. & $\%$ & No. & $\%$ & \\
\hline $\begin{array}{l}\text { Good } \\
>60\end{array}$ & 5 & 14.3 & 3 & 12.0 & 8 & 13.4 & \multirow{4}{*}{$\begin{array}{l}\chi^{2}=0.07 \\
\mathrm{P}=0.965\end{array}$} \\
\hline $\begin{array}{c}\text { Fair } \\
60-\end{array}$ & 12 & 34.3 & 9 & 36.0 & 21 & 35.0 & \\
\hline $\begin{array}{c}\text { Poor } \\
90-120\end{array}$ & 18 & 51.4 & 13 & 52.0 & 31 & 51.6 & \\
\hline Total & 35 & 58.4 & 25 & 41.6 & 60 & $\begin{array}{c}100 . \\
0\end{array}$ & \\
\hline
\end{tabular}

Table (5) : Insight into mental illness distribution by quality of life (QOL) of the studied schizophrenic patients $(n=60)$ :

\begin{tabular}{|c|c|c|c|c|c|c|c|c|c|}
\hline \multirow{3}{*}{ QOL } & \multicolumn{8}{|c|}{ Insight } & \multirow{3}{*}{$\begin{array}{l}\text { Test of } \\
\text { significance }\end{array}$} \\
\hline & \multicolumn{2}{|c|}{ Good } & \multicolumn{2}{|c|}{ Fair } & \multicolumn{2}{|c|}{ Poor } & \multicolumn{2}{|c|}{$\begin{array}{c}\text { Total } \\
(n=60)\end{array}$} & \\
\hline & No. & $\%$ & No. & $\%$ & No. & $\%$ & No. & $\%$ & \\
\hline Good & 2 & 18.2 & 1 & 4.8 & 5 & 17.8 & 8 & 13.3 & \\
\hline Fair & 3 & 27.3 & 4 & 19.0 & 14 & 50.0 & 21 & 35.1 & $\chi^{2}=9.823$ \\
\hline Poor & 6 & 54.5 & 16 & 76.2 & 9 & 32.2 & 31 & 51.6 & $\mathrm{P}=0.044^{*}$ \\
\hline Total & 11 & 18.4 & 21 & 35.0 & 28 & 46.6 & 60 & 100.0 & \\
\hline
\end{tabular}


Table (6): Insight into mental illness distribution by psychosocial functioning of the studied schizophrenic patients $(n=60)$ :

\begin{tabular}{|c|c|c|c|c|c|c|c|c|c|}
\hline \multirow{3}{*}{$\begin{array}{l}\text { Psychosocial } \\
\text { functioning }\end{array}$} & \multicolumn{8}{|c|}{ Insight } & \multirow{3}{*}{$\begin{array}{c}\text { Test of } \\
\text { significance }\end{array}$} \\
\hline & \multicolumn{2}{|c|}{ Good } & \multicolumn{2}{|c|}{ Fair } & \multicolumn{2}{|c|}{ Poor } & \multicolumn{2}{|c|}{$\begin{array}{c}\text { Total } \\
(n=60)\end{array}$} & \\
\hline & No. & $\%$ & No. & $\%$ & No. & $\%$ & No. & $\%$ & \\
\hline Good & 2 & 18.2 & 3 & 14.2 & 14 & 50.1 & 19 & 31.6 & \\
\hline Fair & 3 & 27.3 & 7 & 33.3 & 8 & 28.5 & 18 & 30.1 & $\chi^{2}=9.654$ \\
\hline Poor & 6 & 54.5 & 11 & 52.3 & 6 & 21.4 & 23 & 38.3 & $\mathrm{P}=0.047 *$ \\
\hline Total & 11 & 18.4 & 21 & 35.0 & 28 & 46.6 & 60 & 100.0 & \\
\hline
\end{tabular}

Table (7): Insight into mental illness distribution by motivation and energy of the studied schizophrenic patients $(n=60)$ :

\begin{tabular}{|c|c|c|c|c|c|c|c|c|c|}
\hline \multirow{3}{*}{$\begin{array}{l}\text { Motivation } \\
\text { and Energy }\end{array}$} & \multicolumn{8}{|c|}{ Insight } & \multirow{3}{*}{$\begin{array}{c}\text { Test of } \\
\text { significance }\end{array}$} \\
\hline & \multicolumn{2}{|c|}{ Good } & \multicolumn{2}{|c|}{ Fair } & \multicolumn{2}{|c|}{ Poor } & \multicolumn{2}{|c|}{$\begin{array}{c}\text { Total } \\
(\mathbf{n}=60)\end{array}$} & \\
\hline & No. & $\%$ & No. & $\%$ & No. & $\%$ & No. & $\%$ & \\
\hline Good & 2 & 18.1 & 5 & 23.8 & 13 & 46.4 & 20 & 33.3 & \\
\hline Fair & 4 & 36.3 & 3 & 14.3 & 6 & 21.4 & 13 & 21.6 & $\chi^{2}=6.758$ \\
\hline Poor & 5 & 45.5 & 13 & 61.9 & 9 & 32.2 & 27 & 45.1 & $\mathrm{P}=0.149$ \\
\hline Total & 11 & 18.4 & 21 & 35.0 & 28 & 46.6 & 60 & $\overline{100.0}$ & \\
\hline
\end{tabular}




\section{$\underline{\text { DISCUSSION }}$}

While interest has grown steadily in understanding how persons with schizophrenia appraise their disorder and subsequently move towards recovery, the nature of the impact of awareness or admission of schizophrenia on various domains of quality of life has remained a matter of debate. Research has paradoxically linked awareness of illness to both better function outcomes and lesser hope and self-esteem. One possible explanation for these findings is that acceptance of having schizophrenia may impact outcomes differently depending on the meanings the person attaches to this acceptance, particularly whether he or she accepts stigmatizing beliefs about mental illness.

The present study revealed that nearly half of the studied schizophrenic patients had poor score of insight, while only less than quarter of the studied subjects had good insight. This may be related to the assumption that the impaired insight is associated with schizophrenia and the patients who had poor insight into their illness had significantly longer episodes of non adherence that are more likely to involve a complete cessation of medication This finding is consistent with the World Health Organization's

(WHO) International Pilot Study of Schizophrenia in different cultures which found that more than $90 \%$ of the subjects with schizophrenia manifested poor insight. In another study, between $50 \%$ and $80 \%$ of patients diagnosed with schizophrenia were shown to be partially or totally lacking insight into their mental disorder . The prevalence of poor insight is more severe and pervasive in this population than in patients with schizoaffective or major depressive disorders, with or without psychosis. This result may be explained by the fact that the patient may refuse to accept the label of being a psychiatric patient because of the social stigma. So, the patient may use poor insight as a defense mechanism to protect his identity and dignity.

Rickelman (2004) ${ }^{(20)}$ found that almost $60 \%$ of people diagnosed with schizophrenia had moderate to severe lack of awareness of their mental disorder, 
while $27 \%$ of subjects with schizoaffective disorder and $57 \%$ of patients with manic depression were "severely unaware of specific symptoms such as delusions, thought disorder, disordered speech, restricted affect, anhedonia, a sociality, and other illness manifestations".

Regarding the score of quality of life, the finding of the present study indicated that more than half of the studied schizophrenic patients had poor quality of life, while about thirteen percent of them had good quality of life. In the same direction, Nippon Kosho(2003) $)^{(21)}$ conducted a study to clarify the concept of quality of life (QOL) and to identify appropriate goals for future studies on the QOL of patients with schizophrenia, he found that patients with schizophrenia had lower total QOL scores compared to non-disabled persons and patients with depression. These results may be explained by factors associated with their QOL such as: personal characteristics, lifestyle, mental symptoms, adjustment (to relations with family, friends and others), social support, selfesteem, and autonomy.

Regarding the relation between insight into mental illness and quality of life (QOL) of the studied schizophrenic patients, the present study revealed that the highest frequency of patients with good insight was observed among the group with poor quality of life, while the highest frequency of patients with poor insight was noticed among the group with fair quality of life. Also, the highest frequency of patients with fair insight was observed among the group with poor quality of life.

In relation to insight into mental illness distribution by psychosocial functioning of the studied schizophrenic patients, the present study revealed that the highest frequency of patients with good insight was observed among the group with poor psychosocial functioning, while the highest frequency of patients with poor insight was noticed among the group with good psychosocial functioning. Also, the highest frequency of patients with fair insight was observed among the group with fair psychosocial functioning. This may indicate that the impaired insight plays a significant role in the formation and maintenance of psychosocial functioning.

In this respect Ilanit HassonOhayon(2006) ${ }^{(22)}$ examined the nature of the relation between a multidimensional measure of insight and a multidimensional 
measure of quality of life in persons with schizophrenia or schizoaffective disorder and he found that general insight into mental disorder was negatively related to quality of life in the domains of emotional well-being, economic satisfaction, and vocational status. Thus, persons with higher levels of insight into their mental illness reported less emotional well-being, less economic satisfaction, and lower vocational status. Furthermore, insight into the symptoms of mental illness was also found to be negatively related to quality of life in the domain of emotional well-being. This may be also an alteration in some patients who were seen by their interviewer as being more aware of their positive and negative symptoms also expressed higher levels of emotional distress.

In this study, it was found that the highest frequency of patients with good insight was observed among the group with poor motivation and energy, while the highest frequency of patients with poor insight was noticed among the group with good motivation and energy.

The present study finding consistent with a study by Mintz et $\operatorname{al}(2003)^{(23)}$ who conducted a study to assess both psychopathology and insight in schizophrenia.. The authors abstracted measures of five dimensions of insight: "individual's awareness of the mental illness, awareness of the social consequences of the disorder, awareness of the need for treatment, awareness of symptoms and attribution of symptoms to the disorder" from studies which met inclusion criteria and utilized those to create an overall insight index. The relationship of this index with negative and depressive symptoms was then calculated. This analysis revealed that higher levels of insight were linked with increased negative symptoms. This findings may be interpreted as: greater insight has been associated with higher levels of depressive symptoms and higher levels of dysphoria, lowered self-esteem, and decreased wellbeing, and quality of life.

Contradictory findings have also been reported concerning the relationship between insight and QOL in patients with schizophrenia. Whereas previous studies showed an association of increased insight with better QOL, other studies demonstrated an inverse relationship between insight and subjective QOL. Other ones failed to find an association. These 
discrepancies may be attributable, at least in part, to differences between patient samples (groups of patients in different phases of illness, inclusion of patients with diagnosis other than schizophrenia spectrum disorders), and methodological differences among studies.

\section{Conclusion and Recommendations}

The majority of schizophrenic patients often lack insight into their mental illness and having poor quality of life. Insight into mental disorder was negatively related to quality of life in the domains of psychosocial functioning and emotional well-being. Thus, patients with higher levels of insight into their mental illness reported poor psychosocial functioning and emotional well-being. Furthermore, no relation was found between insight into mental illness and quality of life in the domain of motivation and energy and the domain of medication adherence, and sideeffects.

From the results of the present study one can recommend the following:

1- Providing patients and their families with simplified books containing basic information about their mental illness and coping strategies can improve the prognosis.
2-The mental health care professionals need to work on strengthening the therapeutic alliance in order to build up a close relationship with their patients.

3-It may be useful to consider interventions that decrease internalized stigma., for instance, has suggested that it is just as important for interventions to assist in developing a sense of mastery as it is to help enhance insight.

4- Management of schizophrenic patients should includes the reduction of positive, negative and depressive symptoms, the prevention of relapse, the improvement of QoL and the reintegration into the social, familiar and vocational environment.

5- Future interventions and research could be directed to help persons with schizophrenia overcome their negative beliefs and find newer and more adaptive ways to think of themselves and their futures, thus allowing for the acceptance of mental illness to have fewer devastating effects.

6-Psychoeducational programmers to schizophrenic patients should offer the opportunity to focus on insight, QoL and depression. 